\title{
AUDITORIA EM ENFERMAGEM
}

\author{
Maria Vanda de Araujo * \\ Ir. Cleamaria Simões * \\ Celina Lima Silva*
}

RBEn/04

ARAUJO, M.V. e colaboradoras - Auditoria em enfermagem. Rev. Bras. Enf.; DF, 31 : 466-477, 1978.

\section{INTRODUÇAO}

A auditoria em enfermagem é o assunto empolgante do momento nas atividades administrativas de enfermagem, motivo pelo qual nos conduziu a realizar seu estudo identificando seus objetivos, metodologia e validade.

Atualmente, na transição acelerada da enfermagem para um assentamento científico, urge adquirir solidez que a ciência exige em seus conceitos e ação.

A revisão bibliográfica mostra a praticidade de alguns tipos de auditoria, senão em nosso país, pelo menos nos Estados Unidos.

Em nosso meio profissional o despertar à auditoria ainda é incipiente, necessitando consolidar seus fundamentos, estudos adaptativos que se moldem a realidade brasileira.
Tivemos a oportunidade de realizar contatos pessoais com profissionais da área, objetivando apreciar a sua aplicação em Hospitais Municipais e Previdenciários do Rio de Janeiro.

Constatamos a ausência na ação auditorial.

Pareceu-nos que há motivação bastante nos profissionais da coordenação de enfermagem; falta-lhes o necessário conhecimento teórico" como também condições estruturais nas diversas instituições impossibilitando a implantação do processo.

O interesse do grupo intensificou-se a proporção que novos conhecimentos fizeram-se necessários.

Assim sendo, um elemento designado pelo grupo deslocou-se a fim de participar de um curso de auditoria em enfermagem em São Paulo, patrocinado

\footnotetext{
* Alunas do Curso de Mestrado em Ciências da Enfermagem da Escola Ana Neri - UFRJ - 1977.
} 
ARAUJO, M.V. e colaboradoras - Auditoria em enfermagem. Rev. Bras. Enf.; DF, 31 : 466-477, 1978.

pelo Centro São Camilo de Desenvolvimento em Administração da Saúde. Ministrado em 15 horas aula, no periodo de 07 a 11 de novembro. Outro elemento participou também do curso de auditoria realizado durante o XIX Congresso Brasileiro de Enfermagem.

Este acervo de informações nos possibilita transmitir alguma experiência e quiçá, conscientizar outros profissionais sobre a necessidade para esse novo despertar da enfermagem.

\section{LITERATURA}

\subsection{Conceito de Auditoria}

São vários os conceitos de auditoria. A título ilustrativo serão citados:

\subsubsection{Na área contábil}

Para HOLMES 22 auditoria "é o exame de demonstrações e registros administrativos. $O$ auditor observa a exatidāo, integridade e autenticidade de tais demonstrações, registros e documentos."

FERREIRA 9 define auditoria como "exame analítico e pericial que segue $n$ desenvolvimento das operações contábeis, desde o início até o balanço'. O mesmo autor refere a auditoria como sendo "cargo de auditor" e/ou "lugar onde este exerce suas funções".

Para MAUTZ 16 "a auditoria preocupase com a verificação de elementos contábeis e em determinar a exatidão e a fidelidade das demonstrações e relatórios contábeis.

\subsubsection{Na área de saúde}

$\mathrm{Na}$ área de saúde a auditoria está praticamente em fase inicial e já conta com algumas definições consagradas.

DUNN e MORGAN 14 "auditoria é um instrumento de administração utilizado na avaliação da qualidade do cuidado; é a comparação entre a assistência prestada e os padrões de assistência considerados como aceitáveis".

AGUIAR e colaboradores 2 afirmam que "a auditoria médica deve ser explicitada como o conjunto de atividades exercidas com o objetivo de avaliar o trabalho da equipe de saúde, nos seus múltiplos aspectos".

Especificamente no campo da enfermagem DEEKEN 21 define auditoria como "exame oficial dos registros de enfermagem com o objetivo de avaliar, verificar, e melhorar 2 assistência de enfermagem".

Para PHANEUF 14 "auditoria é um método utilizado para avaliar a qualidade do cuidado de enfermagem através dos registros de enfermagem, após a alta do paciente".

\subsection{Objetivos da auditoria}

RIBEIRO 21 enfoca como objetivo central da "auditoria a melhoria da qualidade da assistência de enfermagem que o hospital se propõe oferecer à comunidade, ou que tem por obrigação social oferecer".

FELDMANN 8 além do objetivo citado lembra a motivação da enfermagem a alcançar padrões ideais de assistência ao paciente.

\subsection{Evolução histórica}

Na história da contabilidade a verificação dos fatos e seus registros, devidamente documentados, data do ano 2.600 a.C. Entretanto, somente a partir do século XII, na Inglaterra, esta técnica passou a ser utilizada em maior escala e com o nome atual. 22

A revolução industrial do século XVII deu novas diretrizes à prática auditorial visando atender as necessidades das grandes empresas. 22

No Brasil, a prática da auditoria é recente, contando apenas com aproximadamente quatro décadas de uso oficial. 22 
ARA.JJO, M.V. e colaboradoras - Auditoria em enfermagem. Rev. Bras. Enf.; DF, 31 : 466-477, 1978.

Na área da saúde a verificação da qualidade da assistência ao paciente através de registros do prontuário vem sendo utilizada nos Estados Unidos desde 1918, por iniciativa do médico George Gray Ward, de Nova Iorque. 2, 14, 19 e 21

As primeiras publicações sobre auditoria em enfermagem, datam de 1955, também nos Estados Unidos, onde atualmente se desenvolve no campo hospitalar, de saúde pública e domiciliar. 14, 15

No Brasil, a auditoria tanto na prática médica como de enfermagem dá os seus primeiros passos e tentativas modestas de implantação começam a surgir.

No relatório dos primeiros cinco anos de auditoria médica no Hospital de Ipanema, no Rio de Janeiro, os membros da comissão concluem que o programa é benéfico tanto em termos de fornecimento de elementos para decisões administrativas como para o corpo clínico do Hospital que dispõe de informações seguras para análise das técnicas e programas desenvolvidos. 2

As referências em enfermagem falam da necessidade e condições de implantação de programas de auditoria.4, 14, 21

\subsection{Técnicas de auditoria}

\subsubsection{Métodos}

A técnica auditoral segundo SA 22 utiliza os métodos de retrospecção e análise.

Pela retrospecção verifica os fatos passados situando a observação quanto ao tempo, em períodos já vividos. Não vai diretamente ao fato, mas aos elementos que 0 evidenciam.

A análise constitui a essência da ação auditorial. Verificar sem interpretar, sem orientar e sem criticar é tarefa ineficaz e não interessa aos métodos científicos. A auditoria não se limita a sumples verificação. Os fatos são analisados de- talhadamente pelo auditor, incluindo as condições favoráveis à melhoria do serviço.

PERRONE 19 propõe a "auditoria concorrente que é feita durante a hospitalização do paciente".

CERQUEIRA 4 fala de três tipos de auditoria possíveis de realização no Serviço de Enfermagem:

Auditoria retrospectiva que corresponde a citada por Sá;

A auditoria operacional semelhante a concorrente. realizada enquanto o paciente está hospitalizado e compreende a verificação do prontuário e entrevista com o paciente;

Auditoria de plano de cuidado que se prende a avaliação do plano de cuidado do paciente.

\subsubsection{Classificação da auditoria}

A classificação da auditoria refere-se as necessidades de realização por parte das instituições, sendo mais aplicáveis a área de saúde, a auditoria quanto a forma de intervenção, tempo, natureza e limite.

Quanto a forma de intervenção pode ser interna e externa. No caso de auditoria interna, é praticada por elementos da própria Instituição. Tem como vantagens maior profundidade no trabalho tanto pelo conhecimento da estrutura administrativa como de inovaçōes e expectativas nos serviços. A sua vinculação funcional permite sugerir soluçōes apropriadas. Como desvantagem pode-se citar a dependência administrativa limitando a amplitude das conclusões e/ou recomendações finais do trabalho. Pode haver também envolvimento afetivo do auditor com os elementos realizadores do trabalho invalidando-o.

A auditoria externa é realizada por elementos estranhos a Instituição e por ela contratados para realizar o exame. Apesar do auditor gosar de independên- 
ARAUJO, M.V. e colaboradoras - Auditoria em enfermagem. Rev. Bras. Enf.; DF, 31 : 466-477, 1978.

cia administrativa e afetiva, os seus interesses estão ligados a outra entidade não estando motivado o suficiente para realizar um trabalho profundo, que apresente sugestões adequadas à solução de problemas existentes.

A auditoria interna é preferida, entretanto, existem situações onde é necessária a apreciação do auditor externo.

Quanto ao tempo a auditoria pode ser contínua ou periódica. A contínua avalia em períodos certos, fazendo cobertura integral por exercícios ou períodos. A revisão sempre se inicia a partir da anterior. A auditoria periódica examina também em tempos certos, não se prende porém, a continuidade.

Em relação a natureza a auditoria pode ser normal e especial. No primeiro caso se realiza em periodos certos com objetivos regulares de comprovação. No segundo, atende a uma necessidade do momento.

Quanto ao limite pode ser total ou parcial. A total atinge todos os setores da Instituição e a parcial limita-se apenas a determinados serviços. 22

\subsection{Padrões de desempenho}

O padrão da qualidade do serviço pode ser referido como bom ou não, desde que comparado a um padrão pré-estabelecido.

A ação de enfermagem deve ser avaliada a partir dos resultados advindos da apreciação das atividades aplicadas nos cuidados ao paciente e registrados em seu prontuário. Esse registro é, então, medido e comparado com padrões referidos que definem qual a assistência de enfermagem que deveria ser prestada. 19, 21

Na avaliação da eficiência há a possibilidade de se usar a valiação absoluta ou a avaliação relativa. No prinneiro caso compara-se o profissional a um padrão, atravís de escalas de avaliação e listas de assinalamento. A avaliação relativa compara profissionais entre si. 19, 22

$\mathrm{Na}$ auditoria de enfermagem poderse-ia além "de outros índices utilizar a comparação dos resultados obtidos pela terapêutica com os esperados a partir do prognóstico de enfermagem. 14

Enquanto a enfermagem não possui padrões de avaliação determinados é de bom alvitre utilizar a experiência de outras áreas e/ou países, amoldá-las à realidade local e inferir a própria. A experiência e o método PHANEUF estabelece os padrões de desempenho tendo como base as funções de enfermagem de ANDERSON E LESNICK:

"I - Análise e execução das ordens médicas;

II - Observação de sinais e sintomas;

III - Supervisão dos pacientes;

IV - Supervisão de todo pessoal que participa do cuidado (exceto o médico);

v - Registros e relatórios;

VI - Análise e execução de técnicas e procedimentos de enfermagem;

VII - Promoção de Saúde Pública e Mental do Paciente pela orientação e ensino". 14

Para justificar o padrão de qualidade do serviço de asistência à Saúde é indispensável a utilização do método ou processo auditoral como atividade formal do serviço de Enfermagem. Assim sendo, guiar-se-á por objetivos claros e definidos. 14

\subsection{Limitações da auditoria}

\subsubsection{Limitações de ordem humana}

A enfermagem foi por muito tempo desempenhada, quase que exclusivamente, por indivíduos inabilitados, impedindo um avançar mais rápido e passar para uma enfermagem cientifica, racional e sistemática. Atualmente, novos papéis são exigidos do profissional 
ARA.UJO, M.V. e colaboradoras - Auditoria em enfermagem. Rev. Bras. Enf.; DF, 31 : 466-477, 1978.

levando a modificações profundas nas estruturas das Instituições de Saúde. 11, 12

t urgente que a enfermagem se conscientize de seus novos papéis e se prepare devidamente para executá-los. 110 conhecimento favorece a maturidade no desempenho profissional, garante o progresso e novas descobertas imprescindiveis para estabelecer o arcabouço científico da profissão. ¿ necessário lutar para debelar a ignorância e prevalecer o conhecimento. 18

Como limitações principais da auditoria podem ser citadas:

- avaliação retrospectiva - a auditoria se realiza após a alta do paciente.

- avaliação parcial - a assistência ao paciente é prestada por uma equipe multiprofissional e não apenas pela enfermeira. A auditoria de enfermagem avalia apenas a responsabilidade da enfermagem no cuidado ao paciente. Não permite uma visão global da assistência prestada.

- não tem finalidade punitiva - verifica o cuidado, identifica erros e os analisa. Qualifica a assistência prestada e pode sugerir soluções. As medidas preventivas e corretivas são de responsabilidade administrativa.

- a auditoria não visa a melhoria dos registros - o objetivo principal i melhorar a assistência ao paciente. Embora ,a partir dos resultados possam sugerir açōes no sentido de melhorar os registros, este não é o seu objetivo. ${ }^{14}$

2.6.2. Limitações de ordem administrativa

Entre as dificuldades de ordem administrativa estão: dos;

- dificuldade na mensuração dos da-

- existência de fatores imponderáveis;

- parâmetros não correspondentes à realidade local;
- valores referentes ao hospital e não a cada clínica. 19

O processo auditoral exige pessoal devidamente credenciado com certas caracteristicas de eficiência e desempenho. Isto supōe reestruturação no planejamento econômico, além da possibilidade de implementação de um outro setor de trabalho com área física independente. 19

O auditor, no desempenho de suas funçōes, provavelmente encontrará limitações inúmeras relacionadas com a amplitude do trabalho que poderá realizar de forma proveitosa, inspirando confiança. O auditor trabalha sob limitações de custos e tempo. Informaçōes poderão ser úteis enquanto atuais, perdendo interesse a medida que caducam. As dificuldades encontradas, as vezes, levam o auditor a satisfazer-se com módicos recursos e ingênuos resultados. 16

Outro fator que limita a auditoria, pelo menos na fase inicial é a dificuldade de manter o departamento de auditoria separado e funcionalmente independente dos demais departamentos. Deve, entretanto, haver afinidade entre o Serviço de Enfermagem e o de Audttoria, para que os resultados correspondam ao objetivo. 14. 16

2.7. Condições essenciais de funcionamento nos Serviços de Enfermagem

\subsubsection{Requisitos básicos}

Como requisitos essenciais ao funcionamento da auditoria de enfermagem, destacam-se:

- Serviços de Enfermagem com objetivos claros, precisos e mensuráveis, permitindo combinar as condições de pessoal, ambiente e equipamento com a situação do paciente e compará-los a padrões estabelecidos ou expectativas;

- percepção da assistência ao paciente como responsabilidade multiprofissio- 
ARA.UJO, M.V. e colaboradoras - Auditoria en enfermagem. Rev. Bras. Enf.; DF, 31 : 466-477, 1978.

nal e não apenas de um elemento isolado. O trabalho de todos deve ser avaliaá, cada um dentro de sua especialização;

- estrutura administrativa que permita a Enfermagem planejar, implemenmentar, coordenar e controlar suas atividades com o objetivo de oferecer melhor atenção ao paciente;

- estabelecimento de um guia que permita identificar problemas no serviço para sua devida correção. 21

\subsubsection{Recursos humanos}

A implantação de um sistema de auditoria de enfermagem depende do incentivo da chefe do serviço e da cooperação das supervisoras, chefes de unidades e demais elementos envolvidos no processo auditoral. 14

A chefe do Serviço de Enfermagem é responsável pela qualidade do serviço. Embora não seja membro efetivo da comissão, ela deve acompanhar o desenvolvimento de todo o processo. A escolha dos demais membros é feita por ela, após consideraçōes sobre os requisitos necessários, de conhecimento técnico e integridade reconhecida, envolvimento com o cuidado do paciente, interesse no controle da qualidade e capacidade de trabalho em grupo. O conhecimento técnico implica, pela necessidade da comissão, em englobar várias especialidades como enfermagem médica, cirúrgica, obstétrica, pediátrica e outras. 14

Considerando a inexistência de maiores experiências com relação à quantifícação dos recursos humanos necessários e como não deve haver uma padronização estanque são enfocados aqui, vários modelos de comissōes:

RIBEIRO 21 apresenta, de um modelo americano;

01 diretor assistente do Serviço de Enfermagem;

01 diretor da divisão de escriturários;
01 diretor assistente de educação em serviço;

01 auxiliar de enfermagem;

03 líderes da equipe de enfermagem;

02 enfermeirăs chefes;

Segundo FELDMANN 8, a comissăo deve ser composta de:

Supervisora;

Enfermeiros chefes de unidades;

Enfermeiras de serviço, oscilando entre quatro e 12 elementos, dependendo do tamanho e tipo do hospital. Não participam da comissão a chefe do Serviço de Enfermagem e nem a supervisora ou a chefe do setor de educação.

Segundo KURCGANT 14, a comissão não deve ter menos de 05 enfermeiras, sendo que em Instituiçōes pequenas, pode-se formar uma comissão conjunta, com membros que prestarão serviços a todas as profissōes representadas.

Em qualquer dos modelos de comissão, dentre os membros são escolhidos um coordenador e um secretário. 8, 14, 21

Para que se obtenha um bom andamento do trabalho e desempenho de pessoal, podem ser determinados para cada tipo de unidade padrões baseados nas condições de cada instituição. Para isso há necessidade de planejamento determinando o padrão de cálculo de enfermeiras para auditoria, e as razões de sua variabilidade nas Instituiçōes. Também pode estar baseado em experiências práticas, quando os padrões recomendados não se adaptarem a uma situaçāo particular. Portanto, os cálculos absolutos não podem ser estabelecidos para cada Entidade. 14

\subsubsection{Recursos materiais}

$\mathrm{Na}$ organização e planejamento de um serviço de auditoria, para assegurar seu bom desenvolvimento, considera-se:

- local: o serviço de auditoria deve funcionar em dependências do hospital especialmente destinadas ou em setor 
ARAUJO, M.V. e colaboradoras - Auditoria em enfermagem. Rev. Bras. Enf.; DF, 31 : 466-477, 1978.

comum a outras atividades que se coadunem a ela. Entretanto, faz-se necessário que o serviço gose de independência e privacidade, face as suas características sigilosas. O local deve ter condiçōes para alojar arquivos, escrivaninhas e outros materiais que se tornem indispensáveis.

Nas Instituições que possuem Serviço de Arquivo Médico e Estatístico (SAME), o trabalho é mais fácil, porque os procedimentos para utilização dos prontuários, poderão ser elaborados em conjunto com esse serviço. $O$ local deve ser amplo, o suficiente, para comportar os membros da comissão em suas reuniőes periódicas;

- impressos: os formulários para auditoria são recursos materiais imprescindíveis, nos seus vários modelos e utilização; todos os documentos de orientação, como normas de serviço, impressos de avaliação de funções, tabelas de utilização no processo da auditoria.

Os formulários de auditoria quer preenchidos ou vazios nunca devem ser anexados ao prontuário, assim como nenhuma observação que evidencie que foi auditorado.

A provisão destes recursos deverá ser feita de acordo com o número de leitos hospitalares. Na participação indireta da aquisição de material, cabe a enfermeira da comissão de auditoria fornecer os dados quanto a especificação técnica de cada material.

Tendo em vista a utilização comum dos equipamentos com outros serviços, requer entrosamento com os demais nesta utilização para manter boa harmonia com eles. 4, 8, 14, 16, 19, 21, 22 e 23

\subsection{Procedimento do trabalho audi- toral}

\subsubsection{Plano auditoral}

São equivalentes em expressão as palavras plano, programa, roteiro de verificação.
Plano de auditoria é a "tarefa prellminarmente traçada pelo auditor que se caracteriza pela previsão dos trabalhos que devem ser executados em cada serviço, a fim de que este cumpra integralmente as suas finalidades dentro das normas cientificas da técnica auditoral". 22

Fayol já dizia "o plano é o resultado visado, a linha de conduta a seguir, dentro dos princípios e preceitos da técnica em estudo." 22

O plano de auditorla pode basear-se em experiências anteriores, nos levantamentos iniciais, nas experiências alheias e nas normas especials a cada caso.

f conveniente seguir uma linha de conduta mais ou menos padronizada para alguns setores e uma variável para cada caso.

Doutrinariamente o plano de auditoria pode constar de duas partes: "uma \&lxa, de acordo com os princípios gerais de auditoria que se acham dispostos segundo a prática profissional seguida peln auditor. Outra variável, que constitui a parte de adaptação ao caso especialmente estudado". 22

E importante ter em mente que o plano é um guia seguro, indicando as açסes a serem realizadas, possibilitando:

- a execução fiel de trabalhos de bom nível técnico profissional;

- acompanhamento do progresso de tal execução;

- a manutenção de uma linha certa que não permita omissões.

Tem-se, então, unidade, flexibilidade e precisão no trabalho a realizar.

O plano deve ser suficientemente claro e dizer: "o que é que vaí ser examinado", "quanto de cada coisa será examinado", "quando será feito o exame", por quem e para que". 22

\subsubsection{Implementaçăo}

Não há técnica padrão para análise de registros e documentos. Ha, entretanto, 
ARAUJO, M.V. e colaboradoras - Auditoria em enfermagem Rev. Bras. Enf.; DF, 31 : 466-477, 1978.

alguns principios a serem respeitados como normas:

- exame de instruçōes de serviços expedidos pela administração;

- exame de instruçōes expedidas pelo serviço de enfermagem;

- exame de registros. 22

KURCGANT 14 propōe a realização da auditoria em enfermagem em três etapas, para as quais apresenta modelos de fichas, embasadas pelo método Phaneuf.

$\mathrm{Na}$ primeira são avaliados os dados referentes ao paciente e à Instituição. A ficha pode ser preenchida pelo Serviço de Arquivo Médico e Estatística.

Na segunda, é feita a revisão do prontuário com preenchimento do formulário. Esta etapa é realizada pelo enfermeiro. A revisão dos registros é feita com base nas funçōes de enfermagem. Cada função comporta subcomponentes num total de 50, aos quais são atribuídos valores, somando 200 pontos.

A contagem dos pontos permite classificar a assistência em:

$$
\begin{aligned}
& \text { Excelente - } 161 \text { a } 200 \text { pontos } \\
& \text { Muito boa - } 121 \text { a } 160 \text { pontos } \\
& \text { Boa } \quad-81 \text { a } 120 \text { pontos } \\
& \text { Regular - } 41 \text { a } 80 \text { pontos } \\
& \text { Insuficiente }-\quad 0 \text { a } 40 \text { pontos }
\end{aligned}
$$

Para os itens "não se aplica "usa-se a tabela dos coeficientes de correção.

Na terceira etapa os resultados são analisados e o auditor define a qualidade do serviço. Há complementação dos aspectos considerados importantes na revisão. 14

RIBEIRO21 apresenta um outro rotelro com cinco itens e dezesseis perguntas. A partir da resposta às perguntas, a comissão poderá sugerir medidas para melhoria do padrão assistencial.

CERQUEIRA 4 com base no método Carter orienta a implementação da auditoria operacional em fases:
- estabelecimento de padrōes de acordo com a clínica;

- verificação dos prontuários;

- entrevista com o paciente;

- avaliação e julgamento fínal.

\subsubsection{Relatório de auditoría}

MAUTZ 16 informa que após completar os exames do material auditorado será redigido o relatório e conclusōes do trabalho. $O$ relatório é emitido com o objetivo de informar realizaçōes a serem por sua vez apreciadas pela administração da empresa hospitalar e pelo Serviço de Enfermagem.

"Fm sentido amplo o relatório é um certificado ou apresentação de um estado que o auditor garante existir, porém, com explicaçōes detalhadas, com apresentação das razōes que conduziram o seu parecer". 21

Enquanto que os relatórios visam apresentar um parecer de natureza técnica sobre a exatidão do que é auditorado, sua forma difere da usada para o certificado. O relatório é mais analítico, enquanto o certificado é mais sintético. $O$ relatório analítico tece comentários sobre as demonstraçōes evidenciadas. Esse típo de relatório é mais confidencial e portanto não se destina a publicação. "Um relatório é a expressão de uma opiniāo e não uma garantia feita pelo auditor. O certificado é, por sua vez, mals garantia do que opiniāo". 21

"A forma do relatório que será entregue a Chefe do Serviço de Enfermagem é estabelecida pela comissão de auditoria. Inclui número de casos que foram julgados refletindo no total em cuidado como excelente, muito bom, bom, regular e insuficiente". 14

No conteúdo deve constar uma síntese estatística, além da descrição dos casos auditorados. Um dos objetivos do relatório é permitir as devidas comunicaçōes com os setores de enfermagem visando um aperfeiçoamento na assistência ao 
ARAUJO, M.V. e colaboradoras - Auditoria em enfermagem. Kev. Bras. Enf.; DF, 31 : 466-477, 1978.

paciente, quer pela melhoria do plano assistencial, quer pela busca de uma sistematização nos registros das açōes d’ enfermagem. 14

A apresentação do relatório traduz o cuidado e desvelo do auditor, sua responsabilidade e capricho. A forma de apresentação deve ser muito boa. Confeccionado em papel de boa qualidade, datilografado, sem erros e tecnicamente escritos. Os detalhes são também importantes na apresentação. $€$ recomendável que o relatório tenha os seguintes dados:

- período a que se refere;

- data de sua elaboração;

- número de ordem

- descrição dos casos auditorados;

- conclusões;

- assinatura do auditor. 22

KURCGANT 14 diz que a apresentação gráfica dos resultados é facilmente vizualizada, permitindo a comparação entre os padrōes ideais com a extração de conclusōes quanto ao nível e qualidade da assistência.

3. CONDIÇÓES ATUAIS DA PRATICA AUDITORAL NOS HOSPITAIS PREVIDENCIARIOS E MUNICIPAIS DO RIO DE JANEIRO

Junto as divisōes de enfermagem foram colhidas informaçōes sobre a prát:ca auditoral especifica de enfermagem nos Hospitais Previdenciários e Municipais da cidade do Rio de Janeiro.

As informaçōes não podem ser generalizadas pois foram colhidas a nivel de coordenação. Teriam sido mais precisas se tomadas junto ao serviço de enfermagem de cada hospital.

A rigor não existe nenhum serviço de auditoria nas Instituiçōes citadas. Entretanto, todas estão motivadas para a necessidade de implantação do processo. Uma tentativa a título experimental, $\mathrm{em}$ fase inicial, foi constatada numa Entidade. Algumas estão partindo da avaliação de desempenho funcional e da qualidade de assistência. Outras fizeram levantamento de situação e estão melhorando condiçōes locais e conscientizando o pessoal hospitalar da necessidade do programa de auditoria.

Uma entidade dispõe de uma "Comissão de Auditoria", entretanto, as atividades exercidas não correspondem à auditoria de enfermagem. Talvez se enquadre mais nos esquemas de sindicâncias administrativa, pois para que haja avaliação de situações uma queixa é necessária.

\section{DISCUSSĀO}

RIBEIRO 21 afirma que para implantar um programa de auditoria de Enfermagem não é necessário muito conhecimento especializado. $O$ indispensável é:

"- muita coragem para enfrentar o problema;

- humildade para reconhecer as falhas;

- honestidade de propósitos para dar continuidade à tarefa;

- liderança a fim de criar condiçōes de implantação do sistema de avaliação".

Partindo dos requisitos apresentados pela autora percebe-se que é possível implantar um programa de auditoria de enfermagem. A literatura fala dos benefícios advindos para o doente, os funcionários, o Serviço de Enfermagem, a Instituição e para a profissão de enfermagem.

Um programa de auditoria constitui um alerta constante para o enfermeiro se manter em suas funçōes garantindo a qualidade assistencial, empenhando-se na aquisição de melhores padrōes.

O doente receberá uma assistência cada vez mais aperfeiçoada, o que the assegura recuperação rápida, com menos riscos e principalmente a certeza de receber o que necessita para resolver o seu problema. 
ARAUJO, M.V. e colaboradoras - Auditoria em enfermagem Rev. Bras. Enf.; DF, 31 : 466-477, 1978.

Os funcionários, sabendo da existência do programa serão motivados tanto a prestar melhor assistência como para proceder registros mensuráveis, que indiquem a qualidade do cuidado prestado. Participarão também de treinamentos específicos. importante motivar, porém, evitando espírito competitivo.

O Serviço de Enfermagem contará com retroalimentação constante permitindo replanejamento e correção de deficiências a curto prazo. Como os objetivos da assistência são ideais, o Serviço estará sempre com programas de treinamento em serviço e experimentação de novos métodos e técnicas assistenciais.

Uma assistência eficiente por parte da enfermagem contribui para a valorização pública da Instituição.

A profissão de enfermagem se manterá em busca constante, firmando-se como ciência e adquirindo status.

A auditoria constitui precioso material de pesquisa e ensino, facilitando não só a verificação e validade de modelos e técnicas como permitindo o evoluir histórico de cada instrumento, modalidade assistencial e outros.

Para que seja possível implementar e dar continuidade a um programa de auditoria o Serviço de Enfermagem do Hospital deve trabalhar possibilitando mensuração, por conseguinte, apresentando padrōes determinados, acreditando que a aqualidade assistencial será obtida desde que a equipe seja movida pelo objetivo proposto. Plano de cuidados, prescrição de enfermagem, passarão, assim, a fazer parte do dia-a-dia de cada enfermeiro. $O$ planejamento da assistência ao paciente, a supervisão das atividades do pessoal auxiliar, a preocupação com a documentação de enfirmagem forçarão o enfermeiro a assumir a sua função específica e delegar determinadas, funçōes, tumbém importantes, mas nāo necessariamente executadas por ele, como fazer pedidos de material, atender telefone, transcrever prescr :'jōes inédicas.
No contexto da realidade brasileira atual, a enfermagem não tem ainda recursos para oferecer condiçōes que favoreçam estabelecer padrão ideal na assistência de enfermagem. Motivo pelo qual é urgente, que os enfermeiros, atinJam um modelo minimo de assistêncis qualitativa como suporte para alcançar metas mais apuradas e pertinentes à enfermagem cientifica.

Atingindo o padrão proposto, necessário se faz revê-lo, exigindo sempre mais paulatinamente outro "plateau" de qualidade.

Sendo, por conseguinte, a auditoria em enfermagem um processo mediante 0 qual as açōes de enfermagem são examinadas, mensuradas e avaliadas em confronto com esses padrōes, sucessivamente o desenvolvimento da profissão como ciência, será constante, consistente e progressiva.

\section{CONCLUSOES E RECOMENDAÇOES}

A auditoria e menfermagem é um processo exigente. Requer dinamização constante de toda equipe de enfermagem, atenção sempre voltada para o desempenho das açōes de enfermagem, integração na equipe, visando os interesses convergidos num ponto focal. Este tem a propriedade de produzir abertura através dos objetivos que norteiam o desempenho das açōes profissionais em busca da melhor qualidade no tendimento do ser humano.

A auditoria em enfermagem como entidade da administração do serviço de enfermagem, constitui atualmente um recurso técnico disponível àqueles profissionais que almejam conquistar o desempenho qualitativo aprimorado aos seus clientes.

Enquanto a tecnologia distancia os homens, a enfermagem através dela, está envidando esforços a realização de uma ação essenciaimente humana - aproximação do ser humano carente para iden- 
ARAUJO, M.V. e colaboradoras - Auditoria em enfermagem. Rev. Bras. Enf.; DF, 31 : 466-477, 1978.

tificar suas necessidades e tentar superá-las.

Muitos conhecimentos imprescindíveis são ainda necessários - como o estudo de tempo e movimento, definição de organização e métodos, como também análise de sistema para que a auditoria de enfermagem tenha pleno êxito. Na sua ausência, porém, nada impede que haja esforços visando as primeiras tentativas no sentido de elaborar padrāo de desempenho utilizando na mensuração e avaliação. Segundo WEBSTERS "os padrōes funcionam com regras para mensuração de qualidade, quantidade, extensão e valor".

A enfermagem, profissāo liberal que ora busca consolidar seu "status" entre as profissōes técnico-científicas, é possuidora de campo fértil para descobertas. Tem como objetivo básico criar seus conceitos e teorias que garantam a sistematização específica. A auditoria em enfermagem vem dar a sua contribuição uma vez que requer conhecimento preciso, definições exatas, como também proporcionar heuristicamente maior facilidade para pesquisa.

Assim, à guisa de contribuição são apresentadas as seguintes recomendações:

1. Considerando que para a ação auditoral é necessário uma prévia estruturação administrativa do serviço de enfermagem;

Recomenda-se que esforços devem ser feitos no sentido de definir os objetivos da enfermagem, para que, se estabeleçam os elementos estruturais possibilitando a implementação do processo de auditoria.

2. Considerando a necessidade da intervenção da administração hospitalar para a realização da auditoria em enfermagem;

Recomenda-se que se estabeleça a integração necessária entre esses dois ele- mentos para que estudem conjuntamente o serviço auditoral, seus requisitos básicos e vantagens para criar condiçōes a sua implementação no hospital.

3. Considerando que muitos hospitais ainda se limitam ao simples atendimento ao paciente vendo-o apenas como um elemento comercial, olvidando-se que $\dot{\epsilon}$ um ser humano e tem o direito de ser atendido como tal;

Recomenda-se que a administraçāo hospitalar reconsidere seus objetivos primordiais e sua filosofia e decida, juntamente com o Serviço de Enfermagem, reformular as metas que justificam a sua existência e finalidade.

4. Considerando que a auditoria deva ser realizada por profissionais competentes;

Recomenda-se que a Chefe do Serviço de Enfermagem estude e designe enfermeiros com capacidade de discernimento, atualizados e com senso crítico e de decisão, para constituirem a comissão de auditoria.

5. Considerando que a enfermagem científica só é possível onde há qualificação profissional e facilidades físicas adequadas;

Recomenda-se, que a Chefe do Serviço de Enfermagem tenha, em caráter permanente a Comissāo de Educaçāo em Serviço, com o objetivo de dectar as necessidades de aprimoramento profissional dos elementos da equipe de enfermagem.

6. Considerando que a auditoria é um elemento administrativo, ainda recente e desconhecido no ambiente hospitalar;

Recomenda-se que se faça urna revisão do currículo do Curso de Graduaçāo para que o futuro profissional receba 
ARAUJO, M.V. e colaboradoras - Auditoria em enfermagem. Rev. Bras. Enf.; DF, 31 : 466-477, 1978.

orientação necessária conduzindo-o à integração desta nóvel função especifica do enfermeiro, capacitando-o à sua plena execução.

7. Considerando indispensável uma integração entre ensino e o campo de aprendizagem;
Recomenda-se que haja um esforço mútuo dos docentes e dos enfermeiros assistenciais, estabelecendo unidade de ação que favorece o enriquecimento de todos, despertando para um trabalho de equipe, guiados pelo objetivo essencial prestar cuidados de enfermagem que se destaquem pelo nível de qualidade.

\section{BIBLIOGRAFIA}

1. ABDELAH, F. G. - Critérios de avaliação em enfermagem. Traduçāo: C. M. Ribeiro. Revista Brasileira de Enfermagem. 26: (1-2):17-32, 1973.

2. AGUIAR, N. et alii. - Auditoria Médica: teoria $e$ prática. INPS-RJ, 1975, mimeografado.

3. BLOC, D. - Evaluation of nursing care in terms of process and outcome. Nursing Research. 24(4):256-263, Jul./Aug., 1975.

4. CERQUEIRA, L. T. - Auditoria em Enfermagem - Tese de Livre-Docência. UFRJ, 1977.

5. CINCIARULLO, T. I. et alii. - Prescrição de Enfermagem. Experiências de sua aplicaçāo em Hospital Particular. Revista Brasileira de Enfermagem. 27(2) :144-149, abr./jun., 1974.

6. CETTO, L. et alii - Verificaçāo do nivel de assistência de Enfermagem em Hospital Previdenciário Geral, em São Paulo, segundo as necessidades dos pacientes hospitalizados. Revista Enfermagem Novas Dimensōes. 1(4):158-171, set./out. 1975.

7. DOURADO, H. G. - Reflexס́es sobre análise $\mathrm{e}$ avaliaçáo na assisténcia de Enfermagem com vistas a auditoria de Enfermagem. Revista Goiâna de Medicina. 20:115-118, 1974.

8. FELDMANN, M. A., et alii - Administração em Enfermagem. v. 8. São Paulo, I.B.D.O.H. 1974, 78-81 p.

9. FERREIRA, A. B. H. - Novo Dicionário da Lingua Portuguesa. 5 reimpressāo. Rio de Janeiro, Nova Fronteira, $160 \mathrm{p}$.

10. GAUTHIFR, P. H. et alii - Análise do Desempenho Hospitalar. Tradução: M.T. Fraga. São Paulo, Sociedade Beneficente S. Camilo, 1976. 111 p.

11. HORTA, W. A. - Os novos papéis da Enfermeira/o. Revista Enfermagem
Novas Dimensōes. São Paulo, 2(1), mar./abr. Editorial, 1976.

12. A funçāo especifica da Enfermeira/o. Revista Enfermagem Novas Dimensōes. 2(3), jul./ago. 1976. Editorial.

13. HUMEREZ, D. et alii - Unidade Mebólica. Revista Organização e Planejamento. 27 (1): 71-78, jan./mar. 1974.

14. KURCGANT, P. - Auditoria em Enfermagem. Revista Brasileira de Enfermagem. 29(5):330-333, May/1977.

15. LOHMANN, G. - A statewide system of record audit. Nursing Outlook. 25(5) :230-333, May-1977.

16. MAUTZ, R. K. - Principios de Auditoria. Tradução: H. Franco. São Paulo, Atlas, 1976. 400 p.

17. OGLESBY, $M$. et alii. - The development evaluation of a care system: a heuristic model. Nursing Research, 23(4):334-341, Jul./Aug. 1974.

18. OVERSTREET, H. A. - A maturidade mentad. Tradução: O. Schneider. 3. ed. São Paulo, Nacional, 1967, 230 p.

19. PERRONE, O. - Auditoria Médica. Rlo de Janeiro, 1976. Mimeografado.

20. RIBEIRO, A. B. C. - Administreçăo de Pessoal nos Hospitais. 2. ed. Sbo Paulo, LTr, FENAME, 1977, 281$360 \mathrm{p}$.

21. RIBEIRO, C. M. - Auditoria de serviços de Enfermagem. Revista Brasileira de Enfermagem. 25(4):91103, jul./set. 1972.

22. SA, A. L. - Curso de Auditoria. 5. ed. v. 1. São Paulo, Atlas, 1977, 219 p.

23. SECAF, V. - Papel da Enfermeira na aquisição de material técnico. Revista Brasileira de Enfermagem. 28 (1):69-79. Jan/Mar. 1976. 